\title{
Las dos "Tour Eiffel” de Vicente Huidobro: Sentidos icónicos y traducción de poesía visual
}

\section{The two poems "Tour Eiffel" by Vicente Huidobro: Iconic senses and visual poetry translation}

\section{NÚRIA D’ASPRER HERNÁNDEZ DE LORENZO}

\author{
Facultat de traducció i d'Interpretació. Universitat Autònoma de Barcelona \\ Correo electrónico: deasprer@gmail.com; nuria.asprer@uab.cat
}

\begin{abstract}
Abordaremos la traducción de poesía visual basándonos en dos ejemplos seleccionados del periodo vanguardista (1918 y 1921, respectivamente): dos poemas escritos en lengua francesa por Vicente Huidobro. El sentido (en su vertiente tanto sensorial como semántica) y su adhesión a una concepción plural y no inmanente del mismo se examinará mediante el análisis contrastivo de dos poemas visuales que, pese a llevar el mismo título, Tour Eiffel, se derivan de procesos de composición muy diferentes. Uno de estos ejemplos comparte rasgos del género caligramático a la vez que explota las técnicas del cubismo analítico y sintético (d'Asprer 2002); mientras que el otro combina pintura y escritura poética, insertándose el texto en un fondo figurativo del referente temático, y donde el color intenso predomina. Estas dos variantes de iconicidad: iconicidad secundaria (según terminología de G. Sonesson), en el primer caso, e iconicidad directa en el segundo, así como algunas distinciones matizadas entre iconicidad imágica, diagramática y metafórica (Peirce 1903), más sensibles a la naturaleza plural y dinámica de los procesos creativos y de significación, servirán de base para plantear una traducción poética y pensante (Berman 1985) y para analizar el proceso seguido en la elaboración de la misma en castellano.
\end{abstract}

Palabras clave: Iconicidad, Huidobro, Peirce, poesía visual, traducción poética

We will tackle the translation of visual poetry based on two examples selected from the avantgarde period (1918 and 1921 respectively), two poems written in French by Vicente Huidobro. The sense (in both its sensory and semantic aspect) and its relation to a plural and non-immanent conception of it will be examined through contrastive analysis of two visual poems, which, despite carrying the same title, Tour Eiffel, derive from very distinct composition processes. One of these examples shares features of the calligramatic genre, while exploiting analytical and synthetic techniques of Cubism (d'Asprer 2002); while the other combines painting and poetic writing, with the text inserted in a figurative background of thematic reference and where intense colour predominates. These two modalities of iconicity: secondary iconicity (in accordance with G. Sonesson's terminology), in the first case, and direct iconicity in the second, as well as some nuanced 
distinctions between imagic, diagrammatic and metaphoric iconicity (Peirce 1903), more sensitive to the plural and dynamic nature of the creative process and of significance, will serve as a basis for engaging in poetic and reflective translation (Berman 1985) and for analysing the process we have followed in elaborating it in Spanish.

Key words: Iconicity, Huidobro, Peirce, visual poetry, poetic translation

\section{INTRODUCCIÓN}

En un artículo destinado a debatir sobre la cuestión de los sentidos, resulta oportuno escoger la figura emblemática de la Torre Eiffel, no sólo por haber ésta exaltado los sentidos de numerosos creadores y admiradores suyos, sino porque es en sí misma antena y aglutinadora de escrituras y traducciones ${ }^{1}$.

Vicente Huidobro, desde la vertiente experimental que le lleva a explorar las sendas de la reescritura y de los cruces intersemióticos e interlingüísticos, nos lo demuestra muy bien. Con el presente estudio deseamos ampliar una importante vía de análisis centrada en el fenómeno de las variantes. Si el último trabajo que dedicamos a esta cuestión se basaba en las variantes lingüísticas e iconográficas del poema-pintado de Huidobro Moulin², para el trabajo que nos ocupa hemos elegido el duplo formado por sus dos poemas Tour Eiffel. Ambos fueron escritos en francés. Uno de ellos pertenece, al igual que Moulin, a la serie de poemas pintados de 1921; el otro, de factura cubista, data de 1918 y comparte rasgos del género caligramático.

Aunque las obras escogidas para este trabajo se inscriben en el campo de la poesía visual, nuestra finalidad no es establecer unos valores fijos aplicables a la traducción de ésta de forma general. La poesía visual no constituye un campo unitario, valga mencionar la diversidad de rasgos icónicos que revisten las diferentes tendencias de este género que se remonta a la antigüedad. Hemos preferido delimitar la cuestión a dos poemas correspondientes al periodo creacionista de Huidobro que participan de la experimentación vanguardista de inicios del s. XX. Resaltaremos los rasgos singulares y ciertas constantes de estos poemas, ya que es ello lo que debe guiar la traducción a la par que abre pistas para abordar las relaciones texto-imagen en la producción literaria contemporánea ${ }^{3}$.

\footnotetext{
$1 \quad$ Este trabajo amplía una versión preliminar presentada oralmente en el 'II Seminario Internacional Traducción y humanismo: la traducción de los sentidos’. Universidad de Valladolid y Fundación Duques de Soria (Soria, 15-17 de julio de 2014).

$2 \quad$ Cf. D’Asprer 2011: 95-115.

3 Sobre la poesía visual de las vanguardias históricas y sobre sus antecedentes, véase: "La letra y el signo icónico: apuntes sobre poesía visual” (d'Asprer 2007).
} 
Conviene señalar el fundamento interartial que comporta la experimentación creacionista de Huidobro y que queda patente en los dos poemas seleccionados. Si bien 'arte' y 'media' son dos conceptos indisociables, recurriremos al concepto de interartialidad (y no al de intermedialidad) basándonos en la formalización de Walter Moser (2008: 6992) en cuanto a la dimensión medializadora que éste comporta. Según Moser, la estética interartial se sitúa en el origen de la intermedialidad. En el transcurso del análisis, se observará precisamente el efecto que tiene en las variaciones de sentido esta dimensión medializadora de la interartialidad poética4.

El sentido se entenderá como algo que se ejerce desde la escritura, es decir, como proceso de semiosis desencadenado por la interartialidad. Y también como aquello que se produce a través de los sentidos: la vista y el oído en su confluencia. La experiencia sensorial, pudiendo ser considerada como lo más singular del sujeto, es a la vez motor de resignificación. El concepto de iconicidad, elaborado por el semiótico norteamericano Charles Sanders Peirce, servirá de base para ilustrar nuestras hipótesis en relación con la producción de sentido y la creación poética.

La relación entre el creacionismo huidobriano y el cubismo ya ha sido referida por la crítica en diversas ocasiones (de Costa 1984, Benko 1993, Castro 2008, entre otros), pero en la mayoría de los casos la cuestión se aborda desde una perspectiva historiográfica y cultural. Nuestro propósito es ahondar en el aspecto técnico y constructivo del cubismo que determina la composición poética. Como se verá, la singularidad del creacionismo de Huidobro reside precisamente en aplicar el dispositivo constructivo del cubismo plástico a la creación de la imagen nueva ${ }^{5}$, esta última en sintonía con la estética dadaísta.

\section{TOUR EIFFEL DE ViCENTE HUIDOBRo (1918) ${ }^{6}$}

Robert Delaunay, a quien Huidobro dedica el poema, ya había desarticulado la Torre en unos 30 cuadros, a veces dispersando fragmentos analíticamente, otras unificándolos en mosaico, o sintetizándolos metonímicamente en un ángulo preciso. Daba cuenta así del dinamismo de este monumento que constituye una referencia para las formas de expresión

\footnotetext{
4 El concepto de Intermedialidad no nos parece adecuado aquí: como lo observa Müller (2006), dicho concepto opera en un ámbito que incluye factores sociales, tecnológicos y mediáticos; mientras que la Interartialidad corresponde a interacciones entre las artes y los procedimientos artísticos, y se inscribe en una tradición "poetológica".

La imagen, en cuanto aproximación de dos realidades distantes o creación de un hecho nuevo, confirma la conexión del creacionismo respecto al dadaísmo y los inicios del surrealismo, así como la afinidad estética entre Huidobro y Pierre Reverdy. Asimismo, la aplicación de las técnicas cubistas a la creación de la imagen nueva ilustra la oposición manifiesta de Huidobro respecto a la escritura automática surrealista.

6 La primera edición del poema Tour Eiffel, dedicada a Max Jacob, fue publicada un año antes por la revista Nord-Sud (no doble 6-7 de agosto y septiembre de 1917). Se trata de una versión más breve, donde los versos están justificados de la forma convencional, sólo se mantiene el caligrama de la escala musical.
} 
nuevas. Tour Eiffel fue publicado en una plaquette con cubierta ilustrada por La Tour Nord-EstSud-Ouest de Delaunay; en su interior se incluía además una reproducción de La Tour 1910 del artista. Escritos en tinta negra, los versos aparecen diseminados en las páginas de distintos colores de la plaquette. Sobre este soporte, el poema viene a ocupar el lugar de la figura ${ }^{7}$

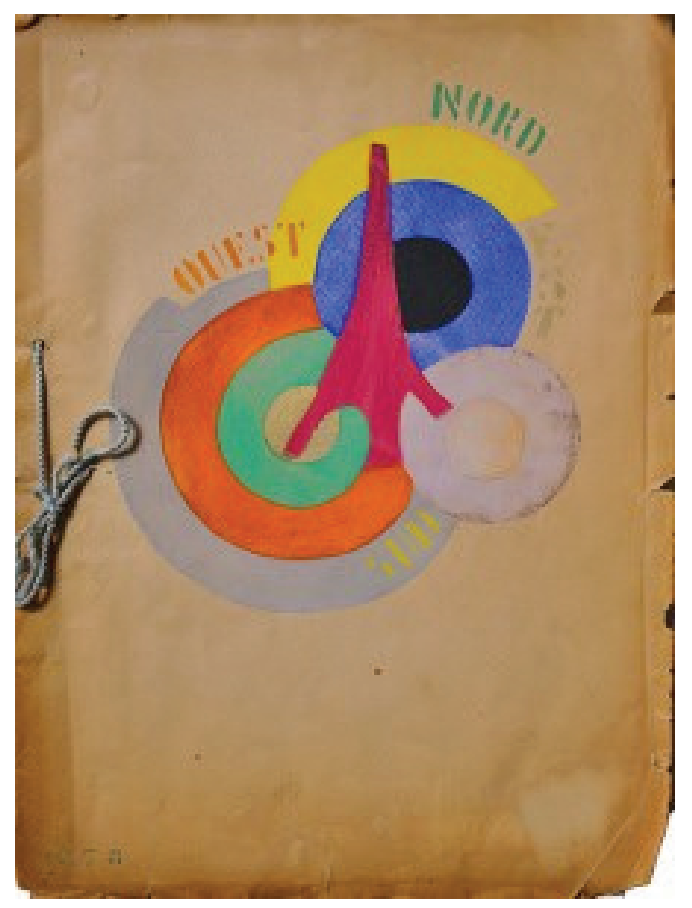

Presentamos aquí la portada y las primeras páginas de la plaquette. Agradecemos la gentileza de la Fundación Vicente Huidobro y de su presidente, Vicente García-Huidobro, por autorizar la reproducción de las ilustraciones que se incluyen en este trabajo. 
ESTUDIOS FILOLÓGICOS

\section{TOUR EIFFEL}

Posse pak VICENTE. HUIDOBRC

Peasuras pas ROBERT DELAUNAY

MADKD -1925

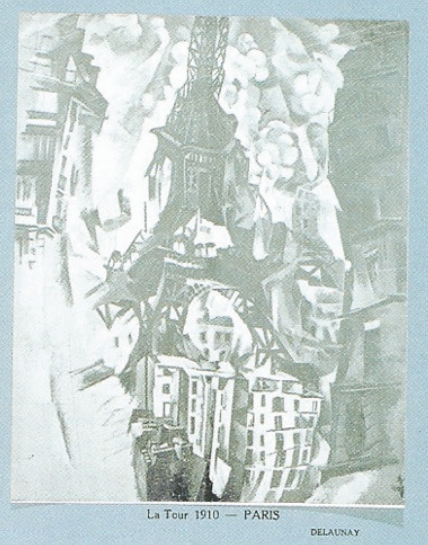

TOUR EIFFEL

A Robert Delaunay

Tour Eiffel

Guitare du ciel

Ta télégraphie sans

Attire les mots

Comme un nosicr les abeilles

Pendant la nuit

La Seine ne coule plus

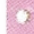

Télescope ou clairon

TOUR EIFFEL.

Et cest tine tuche de mots

Oy un encrier de miel 
Independientemente de la conexión obvia con la pintura que supone un libroobjeto de arte, nos limitaremos a observar la factura del poema y la técnica cubista empleada ${ }^{8}$.

Tour Eiffel

Guitare du ciel

Ta télégraphie sans fil

Attire les mots

Comme un rosier les abeilles

Pendant la nuit

La Seine ne coule plus

Télescope ou clairon

TOUR EIFFEL

Et c'est une ruche de mots

Ou un encrier de miel

Au fond de l'aube

Une araignée aux pattes en fil de fer

Faisait sa toile de nuages

\section{Mon petit garçon}

Pour monter à la Tour Eiffel

On monte sur une chanson

Do

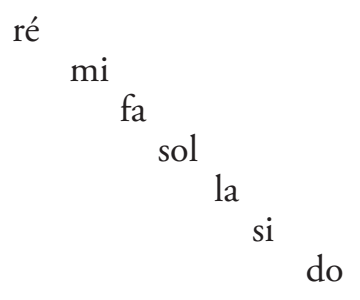

Nous sommes en haut

Un oiseau chante

C'est le vent

Dans les antennes

De l'Europe

Télégraphiques

Le vent électrique

$8 \quad$ Sobre las relaciones plásticas que asocian este poema a la pintura, o las correspondencias entre la construcción arquitectónica de la Tour Eiffel y las técnicas de composición cubistas, véase. d'Asprer 2002: 71 87. Sobre la relación entre iconicidad cubista y formaciones del inconsciente, véase el primer abordaje de este poema en d'Asprer 2003/2007: 77-102. 
Là-bas

Les chapeaux s'envolent

Ils ont des ailes mais ils ne chantent pas

Jacqueline

Fille de France

Qu'est-ce que tu vois là-haut

La Seine dort

Sous l'ombre de ses ponts

Je vois tourner la Terre

Et je sonne mon clairon

Vers toutes les mers

Sur le chemin

De ton parfum

Toutes les abeilles et les paroles s'en vont

Sur les quatre horizons

Qui n'a pas entendu cette chanson

JE SUIS LA REINE DE LAUBE DES POLES

JE SUIS LA ROSE DES VENTS QUI SE FANE TOUS LES

AUTOMNES

ET TOUTE PLEINE DE NEIGE

JE MEURS DE LA MORT DE CETTE ROSE

DANS MA TÊTE UN OISEAU CHANTE TOUTE L'AN-

NÉE

C'est comme ça qu'un jour la Tour m’a parlé

Tour Eiffel

Volière du monde

Chante Chante

Sonnerie de Paris

Le géant pendu au milieu du vide

Est l'affiche de France

Le jour de la Victoire

Tu la raconteras aux étoiles 
El cruce de dos dispositivos de lectura, textual y visual, nos lleva a identificar en el elemento central de la escalera la técnica cubista de la síntesis: la condensación, que en pintura se consigue mediante la superposición de planos o figuras que guardan cierta afinidad formal, aquí se logra mediante una superposición de objetos de naturaleza distinta, cuya conexión significante es de tipo ideográfico y exige la ruptura de la linealidad textual. Este iconograma es una escalera en el sentido utilitario, puesto que le sirve al poeta para "subir" a la Tour Eiffel; pero es a la vez escala musical'. Por otro lado, este elemento de síntesis irradia en el resto del poema de forma analítica: esto lo observamos tanto en la fragmentación plástica que ejerce la rica disposición espacial de los versos, como en la dispersión del significante bajo la forma de diseminación paronomástica:

\begin{tabular}{|l|}
\hline Tour/ autour/jour/coule \\
guitare \\
terre / volière \\
\hline vers \\
mers \\
reine \\
\hline garçon \\
clairon \\
chanson \\
fond \\
ombre / monde / monte \\
ponts \\
vont \\
horizons \\
\hline do...do \\
haut \\
dort \\
oiseau \\
\hline Eiffel \\
Ciel /Miel \\
Abeille \\
\hline Paroles / poles \\
Automnes \\
\hline Chemin \\
Parfum \\
\hline
\end{tabular}

\footnotetext{
9 si bien la ascensión tonal de la escala, subrayada por los versos 'Pour monter à la Tour Eiffel / On monte par une chanson', no obedece al descenso gráfico que la escritura en lenguas europeas impone.
} 


\begin{tabular}{|l|}
\hline Année \\
Parlé \\
\hline Télégraphique \\
Électrique \\
\hline Fil \\
Sonnerie \\
Paris \\
\hline Meurs / mort / rose \\
\hline Toile / étoiles \\
\hline
\end{tabular}

Como, también, en la dispersión de elementos de contenido, empezando por la isotopía musical, que se manifiesta fragmentariamente:

- Guitare

- Clairon (2 veces)

- Chanson (2 veces)

- Do, ré, mi...

- Un oiseau chante

- Je sonne mon clairon

- Chante (5 veces)

- Sonnerie

- El texto de la canción "Je suis la ReINE...".

O la isotopía de la comunicación:

- Télégraphie Sans Fil

- Mots

- Télescope

- Encrier

- Tour Eiffel (en su calidad de antena)

- Antennes

- Télégraphiques

- Vent électrique

- Ailes

- Ponts

- Terre

- Toutes les mers

- Chemin

- Quatre horizons

- Affiche

- Raconteras 
En esta irradiación masiva propia del cubismo analítico, la figura central de la escala musical constituye un eje vertebrador, siendo a la vez caja de resonancia y núcleo generador del poema.

Si las técnicas del cubismo se manifiestan tanto en el terreno de la plástica como en el literario ¿por qué no sostener la posibilidad, por no decir la necesidad, de practicar el cubismo también en la traducción? Así, nuestro esmero mayor será mantener el rasgo definitorio de la fragmentación analítica, por un lado, y por otro lado el de la síntesis, así como una articulación equilibrada entre ambos procedimientos. En el caso que nos ocupa, estos rasgos constituyen la "dominante poética" (Efim Etkind: 1982), que es fundamental mantener en la traducción.

Los elementos de las distintas series isotópicas (música, comunicación, autoreferencialidad de la escritura) aparecen diseminados. Observemos que algunos términos pueden intervenir en varios campos semánticos, ya sea directa o indirectamente. Si la diseminación de elementos corresponde al cubismo analítico, las interconexiones guardan una estrecha relación con la superposición de planos característica del cubismo sintético, tal como se nos presenta en la pintura cubista.

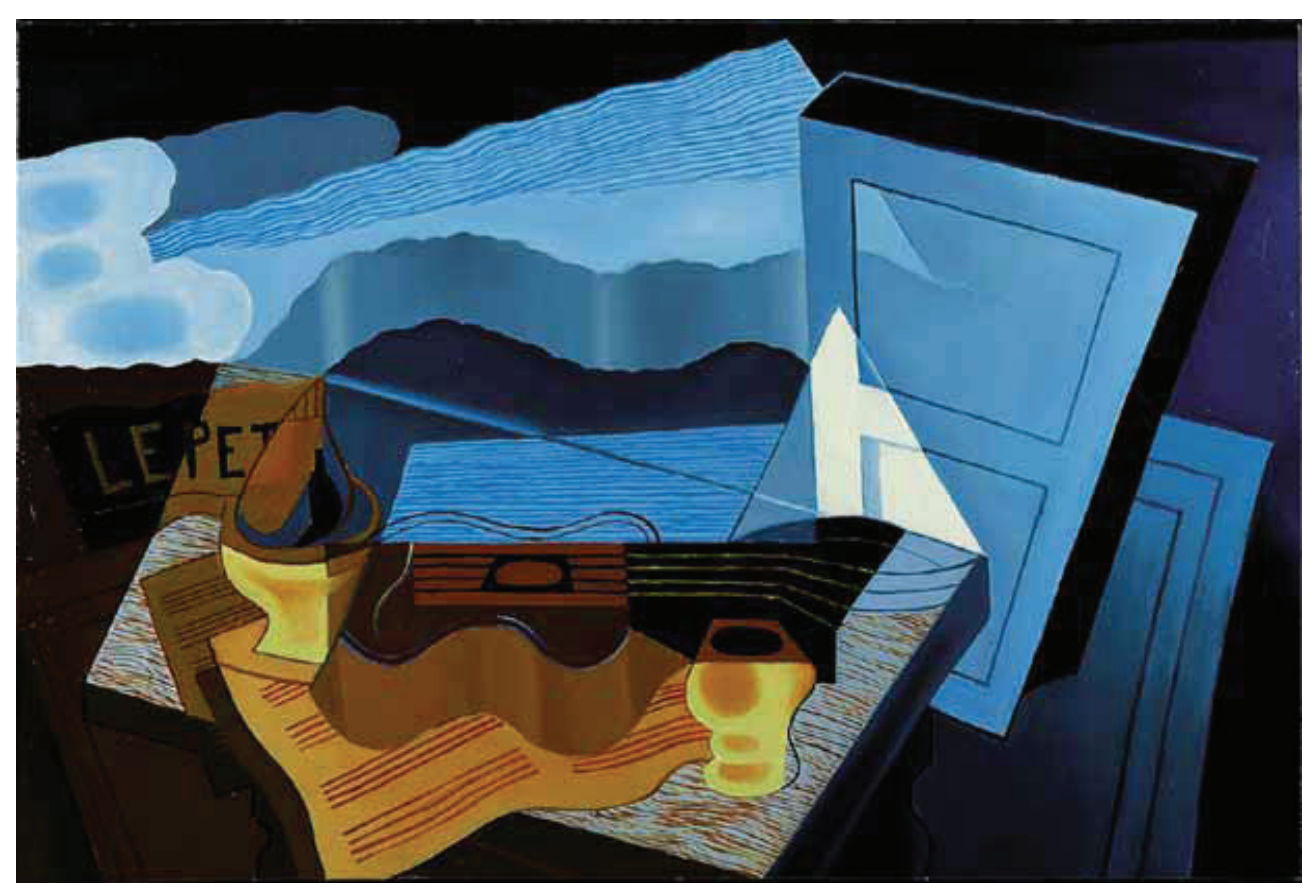


Juan Gris lo ilustra de forma asombrosa en su cuadro Vue de la baie $e^{10}$ (1921), donde superpone las líneas de las cuerdas de la guitarra, con las del agua, las de una partitura, que a la vez es tapete, y las de la madera de la mesa donde están los objetos. Esta imagen central sintética se dispersa analíticamente en el resto del lienzo (obsérvese que el cielo tiene rayas y la doble línea de las montañas dibuja la forma de la guitarra).

En Tour Eiffel, dicho rasgo da lugar a un sistema metafórico que le confiere a la torre un valor instrumental en el sentido más amplio: como instrumento musical e instrumento de comunicación, simultáneamente; es decir, como instrumento poético. Si la escala musical es a primera vista un icono directo o "imagen", según clasificación de C. S. Peirce ${ }^{11}$, el proceso semiótico, esto es el análisis de las asociaciones que dicha imagen activa y luego su interpretación, nos sitúan en el terreno de una iconicidad indirecta y, concretamente, diagramática y metafórica ${ }^{12}$. Diagramática, porque el proceso de composición que hemos analizado se relaciona con las técnicas cubistas; metafórica, porque se da una transferencia, un pasaje a la connotación. En suma, estas categorías corresponden a los diversos niveles de similaridad o de analogía. Recurrir a ellas es una vía para problematizar los conceptos clásicos de representación y de equivalencia. En la unidad del poema, la imagen del iconograma de la escalera funciona como referente (objeto según terminología peirciana), pero un referente complejo y dinámico, por el efecto de las asociaciones ${ }^{13}$.

En la traducción, es preciso prestar atención a estas conexiones significantes. La proximidad de ciertas palabras puede generar asociaciones imprevistas, confluencia de sentidos. Así ocurre con "fil" (hilo) en el verso "télégraphie sans fil", cuya contigüidad respecto al verso "Guitare du ciel", provoca una superposición subliminal con el filamento de las cuerdas de guitarra. Esta inevitable connotación nos impide traducir "telegrafía sin cable". Por si fuera poco, el "fil" (hilo), que es a la vez evocador de la música y de la comunicación, reaparece en el verso "une araignée aux pattes en fil de fer", que en este caso (dado el aspecto articulado de las patas y el color negro de la arańa) podría sugerir las formas filiformes de la escritura (también tenemos la palabra 'encrier'), introduciendo de este modo una riqueza de matices aún mayor en el sistema metafórico. Aquí era difícil mantener el término "hilo", pero hemos optado

10 El título Vue de la baie también pone en escena la técnica del cubismo sintético al operar la doble lectura una síntesis de puntos de vista: 'desde el ventanal', si entendemos 'baie' como baie vitrée, o 'de la bahía', si el vocablo 'baie' designa el objeto de la mirada.

11 Charles Sanders Peirce (1860-1913), Collected Papers. Nos referiremos a la obra de Peirce mediante la abreviatura al uso $(C P)$.

12 Imagen, diagrama y metáfora constituyen tres tipos de proceso icónico en la triada peirciana de los hipoiconos. La imagen es la forma de iconicidad en el sentido estricto, considerada independientemente de su materialización; el diagrama consiste en representar las relaciones entre cosas mediante signos que muestran las mismas relaciones; la metáfora representa una relación semiótica mediante una relación semiótica similar. $C f$. Peirce (CP 2.277 [1903]).

13 No hemos de olvidar que en la semiótica peirciana los signos no son exclusivos, sino que se implican entre sí; de igual modo, el objeto de un signo puede ser inmediato o, como en el presente ejemplo, dinámico. 
por compensar esta pérdida remediando otra, y hemos propuesto "una araña de alámbricas patas": el sintagma preposicional instaura un paralelismo respecto al verso siguiente: "tejía su tela de nubes". Por otro lado, "alámbricas" se integra también en el sistema de asonancias ("télégraphiques", "électrique") presente unos versos después de la escala musical.

En este contexto, y por mucho que el poema no manifieste métrica ni esquemas de rima regulares, el ritmo es crucial. Surge en los intersticios de las palabras, en sus conexiones y sus espacios vacíos: ritmo prosódico y ritmo gráfico interactúan y resaltan la semántica dominante, el vaivén de la torre-antena, su música.

En la lectura transversal de la traducción, deberían observarse los distintos fragmentos del significante cubista: tanto los elementos fónicos que constituyen la caja de resonancia del poema, como los distintos elementos de contenido que tejen las isotopías, principalmente la musical. Tomando en cuenta estos aspectos del significante, nos aproximamos a la "traducción poética y pensante" que proponía Antoine Berman en "La traduction et la lettre ou l'auberge du lointain" (1985: 47) ${ }^{14}$.

Sin embargo, las versiones de este poema que hemos cotejado no prestan atención al significante cubista, o no lo suficiente. Tanto en la traducción de José Zañartu (1957) ${ }^{15}$ como en la de Waldo Rojas (1998) ${ }^{16}$, desaparece por completo la serie de asonancias: clairon / garçon / chanson. 'Mon petit garçon' se convierte respectivamente en 'Hijo mío' y 'Pequeñito mío', que no riman con 'canción'. En nuestra traducción puntuamos el ritmo en una serie breve pero muy concentrada:

Niño de mi corazón
Canción
Do... do

El apego a la ley de la equivalencia en las citadas traducciones también ha obviado un paralelismo que la lengua meta favorecía (Torre /noche / corre), y que habría permitido compensar la reducción inevitable al traducir la serie: Eiffel / ciel / miel / abeille (Eiffel/ cielo/miel/abeja).

'Durante la noche / El Sena ya no corre', es nuestra opción, frente a la de los citados traductores: 'Durante la noche / El Sena deja de correr'. Cabe indicar que se trata de traducciones yuxtalineales. Aparte de esto, el lapsus 'cantarás' como traducción de 'raconteras' en la versión de Zañartu es casi invisible en un marco eminentemente musical - a menos que sea una opción voluntaria, ya que "cantar" no deja de corresponder al decir o contar épico. Por lo demás, la versión de Rojas es más literal, y su traducción de 'sonnerie' por el diminutivo 'campanilla', resulta algo chocante.

14 Se puede consultar una versión castellana de la introducción a este ensayo en Doletiana, revista de traducció Literatura i Arts, No4 [http://webs2002.uab.es/doletiana/Catala/Doletiana4/Doletiana4.html].

Vicente HUIDOBRO, Obra selecta, Luis Navarrete Orta (ed.). (1989: 55).

16

Vicente HUIDOBRO, Obras poéticas en francés, Waldo Rojas, trad. (1998: 177-185). 
Teófilo Cid llevó a cabo otra de las traducciones para la edición Obras Completas, dirigida por Braulio Arenas (1964). Y existe una primera traducción de Cansinos-Assens, casi contemporánea al original y con puntuación final en las estrofas (Revista Cervantes, septiembre de 1919: 82-84). En la edición crítica de Cedomil Goic, dedicada a la obra poética de Huidobro, se reproduce otra versión española de Cansinos-Assens de 1926 con la puntuación rectificada (Índice: 133-135), y en ella se corrigen algunos gazapos y errores de tipografía ${ }^{17}$. Esta traducción es algo diferente y, en ciertos aspectos, puede parecer menos afortunada que la de Zañartu y la de Rojas: se recurre, por ejemplo, a términos más estéticos ('urdía' en lugar de 'tejía' o 'hacía para el verso 'faisait sa toile de nuages'), que aunque no estorban no aportan nada en el sentido de las técnicas cubistas que nos atañen. Además, en lugar de mantener el patronímico francés "Jacqueline", recurre al inusual equivalente "Jacobina", una opción que, dadas las resonancias revolucionarias, resulta adecuada al tono del poema. También observamos la insistencia del pronombre 'Yo' en la letra de la canción (Yo soy la reina... Yo soy la rosa...), calco innecesario según la convención gramatical en nuestra lengua, aunque aquí se podría aceptar el énfasis. Por otro lado, se simplifica la connotación de la torre que produce el vocablo volière (pajarera) traduciéndolo por 'jaula', una opción que no se ajusta ni a las proporciones ni a la connotación estética del monumento parisino.

De la primera versión publicada en Nord-Sud existe una traducción catalana de J. A. V. publicada en la revista barcelonesa El Camí (Barcelona, 2 de febrero 1918: 11). A continuación, presentamos nuestra propia traducción seguida de un breve comentario.

\section{TORRE EIFFEL}

Torre Eiffel

Guitarra del cielo

Tu telegrafía sin hilos

Atrae a las palabras

Como un rosal a las abejas

Durante la noche

El Sena ya no corre

Telescopio o clarín

\section{TORRE EIFFEL}

$Y$ es una colmena de palabras

$\mathrm{O}$ un tintero de miel

17 Vicente Huidobro, Obra poética. Cedomil Goic (ed.). 2003: 621-623. 
En la profundidad del alba

Una araña de alámbricas patas

Tejía su tela de nubes

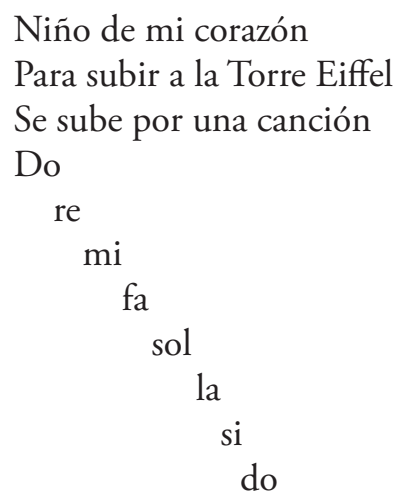

Ya estamos arriba

Un pájaro canta

Es el viento

En las antenas

De Europa

Telegráficas

El viento eléctrico

\section{Allí abajo}

Los sombreros echan a volar

Tienen alas pero no cantan

Jacqueline

$$
\text { Hija de Francia }
$$

¿Qué ves allí arriba?

El Sena duerme

Bajo la sombra de sus puentes

Veo la tierra girar

Y hago sonar mi clarín

De mar a mar

Por el camino

De tu perfume

Todas las abejas y las palabras se alejan 
Por los cuatro horizontes

Quién no ha oído esta canción

\author{
SOY LA REINA DEL ALBA DE LOS POLOS \\ SOY LA ROSA DE LOS VIENTOS QUE MARCHITA \\ CADA OTOÑO \\ Y REPLETA DE NIEVE \\ MUERO CON LA MUERTE DE ESTA ROSA \\ EN MI CABEZA CANTA UN PÁJARO TODO EL AÑO
}

Fue así como un día la Torre me habló

Torre Eiffel

Pajarera del mundo

$$
\text { Canta Canta }
$$

Campana de París

El gigante colgado en medio del vacío

Es el cartel de Francia

\title{
El día de la Victoria \\ Se la contarás a las estrellas
}

En esta versión se observan diversas series de asonancias, así como la presencia recurrente de ciertos fonemas evocadores de la sonoridad del vocablo 'Torre'. Por ejemplo: torre / corre / guitarra / tierra / re.

Este fenómeno, en su conjunto, no sólo pone de relieve la figura de la Torre sino que además confirma el valor sintético en virtud del cual la asociábamos antes a un instrumento: la música, encarnada aquí en la nota re, irradia en el poema. De este modo, la traducción, la nueva lengua, interviene en el procedimiento cubista y reactiva el proceso creativo.

Hasta aquí la traducción no reviste dificultades: ha bastado con traducir "corre" en vez de "fluye". Sin duda alguna, esta homofonía más acusada que en el texto de partida ("tour" / "coule", "torre" / "corre") permite compensar la pérdida que se había producido en otro sector ("Eiffel" / "ciel", "Eiffel" / "cielo").

La brillante paronomasia producida por "Je meurs de la mort de cette rose", donde se oye: meurs de / mort de, así como "amor" (la mort), no ha podido ser reproducida. Y no nos hemos esforzado en ello por dos razones: porque era posible desplazar ese procedimiento a otro segmento del poema, que se presentará a continuación, y porque era importante conservar la doble lectura que contiene el enunciado: 
- 'muero con una muerte parecida a la de la rosa'

- 'muero debido a la muerte de la rosa'

Nuestra traducción "muero con la muerte de esta rosa” permite ambas lecturas; y aunque la paronomasia queda atenuada, ha sido desplazada a otros sectores. Por ejemplo, al verso "de mar a mar", traducción que enfatiza la asonancia del original "vers toutes les mers". Esta opción nos interesaba mucho ya que, por un lado, la aliteración y las segmentaciones hacen emerger palíndromos:

\section{Mar a mar ara \\ Mar a mar ama}

Y, por otro lado, este encadenamiento de base palindrómica movilizaba una lectura en continuo (maramaramaramara...), muy evocadora de la idea de infinito que el original ("vers toutes les mers") presentaba en el plano del contenido. Además, permitía recuperar el significante "amor" presente en el verso "je meurs de l(a mor $) \mathrm{t}^{18}$ de cette rose" anteriormente evocado. De este modo, el bilingüismo de Huidobro subyacente en el original queda actualizado.

Otros palíndromos que produce nuestra traducción, sin mérito alguno ya que la lengua española lo impone, son:

$\begin{array}{ll}\text { Atrae a las palabras } & \text { ala } \\ \text { como un rosal a las abejas } & \text { salalas }\end{array}$

Las "alas" que la lengua española ha hecho surgir se integran en el ambiente aéreo facilitado en el original por "nuages", "vent", o "s'envolent" y, sobre todo, por "ailes", que aparece una vez en el poema. Nuestro procedimiento en la versión castellana vendría, así, a reforzar la motivación.

En la versión que proponemos se pueden identificar fenómenos de asonancias más extensos, con grados de homofonía variables. Por ejemplo, el verso "toutes les abeilles et les paroles s'en vont" se ha traducido por "todas las abejas y las palabras se alejan", que resulta más rico en asonancias que "se van", dada la presencia de "abejas". En cuanto al verso "les chapeaux s'envolent / ils ont des ailes mais ils ne chantent pas", conviene señalar la doble lectura, denotativa (del sombrero como tal ya que tiene alas), y connotativa (del pájaro metafórico). En francés, dicha metáfora queda reforzada por el paralelismo oiseau/ chapeaux. A falta de un fonetismo eficaz, se introduce un sintagma verbal que despliega la imagen condensada. Nuestra versión "echan a volar" permite compensar la imposibilidad de leer "pájaros" detrás de la palabra "sombreros". Esta opción, por otro lado, nos permitía reforzar dos redes asonánticas contiguas: echan, cantan / volar, girar, sonar, mar a mar.

$18 \quad$ El paréntesis es nuestro. 
En suma, el dispositivo cubista del poema pone de relieve el fundamento interartial. Por un lado, recurre a sistemas metafóricos para resaltar fragmentos isotópicos del contenido propios de la tendencia analítica del cubismo y, por otro lado, se resaltan dichos elementos mediante rimas o juegos paronomásticos, efectos de musicalidad en adhesión con el tema nuclear. Un brillante ejemplo de sistema metafórico es el que parte del juego fónico ciel, miel, Eiffel y que converge en la lexía "abeilles", que en cierto modo los sintetiza al tiempo que irradia isotópicamente en otros sectores del poema (ruche de mots / encrier de miel). Esta síntesis es tanto más rica cuanto que condensa el fonetismo francés de los tres vocablos junto con el sentido de lo aéreo que éstos contienen o sugieren: lo aéreo del cielo, de la antena de la Tour Eiffel que es "guitare du ciel", del vuelo de la abeja.

En la traducción, se trata de preservar en la medida de lo posible estos rasgos sensibles, aunque ello conlleve ciertos cambios o desplazamientos. Pero la traducción siempre comporta una pérdida, siempre queda algo por colmar. Así, hemos preferido preservar el sistema metafórico, el vaivén entre análisis y síntesis, pese a la pérdida de la lexía "abeilles": no era posible substituir el vocablo "abeja" en aras de un fonetismo más afín al original porque con su miel-tinta se han tejido las palabras del poema.

\section{El POÈME PEINT "Tour EIfFel" (1922)}

Posteriormente, Huidobro concibió otro poema titulado Tour Eiffel para la serie de 13 poemas-pintados que se expusieron en el teatro Édouard VII de París bajo el lema: "Salle XIV". Tras el cierre de dicha exposición dos días después de su inauguración, este poema-pintado, así como los demás de la serie, se extravió. Hoy se conserva una reproducción del original realizada a partir de un boceto y de un documento fotográfico.

Presentamos a continuación el poema pintado reproducido a semejanza de la versión original, seguido del boceto que la precedió, donde Huidobro anotó indicaciones prácticas. Por último, nuestra traducción personal. Se trata de una versión inicial, atenta al ritmo más que a reproducir las rimas de forma idéntica. En una fase ulterior se adoptará el formato del poema-pintado que le corresponde. ${ }^{19}$

\footnotetext{
19 Poema pintado reconstruido. Primera edición de la serigrafía, 2001. Catálogo de: Salle XIV. Vicente Huidobro y las artes plásticas, Museo Nacional Reina Sofía, Madrid, 2001. P. 34.
} 


\section{ESTUDIOS FILOLÓGICOS}

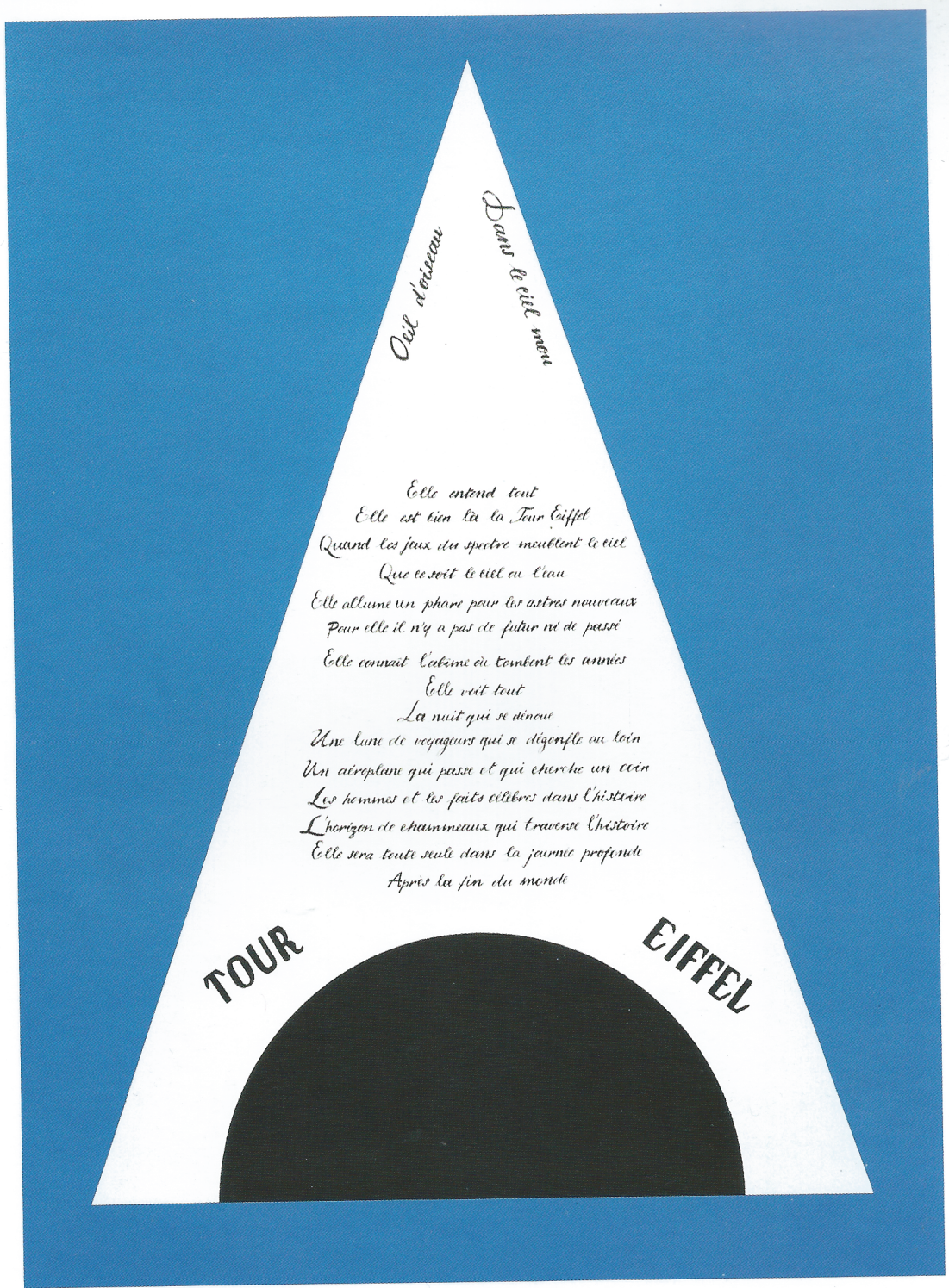

15. vicente huidobro: Tour Eiffel, poema pintado reconstruido a partir de un documento fotográfico y un boceto. Salle XIV, primera edición, 2001

Serigrafía, $73 \times 53 \mathrm{~cm}$

Museo Nacional Centro de Arte Reina Sofía, Madrid 


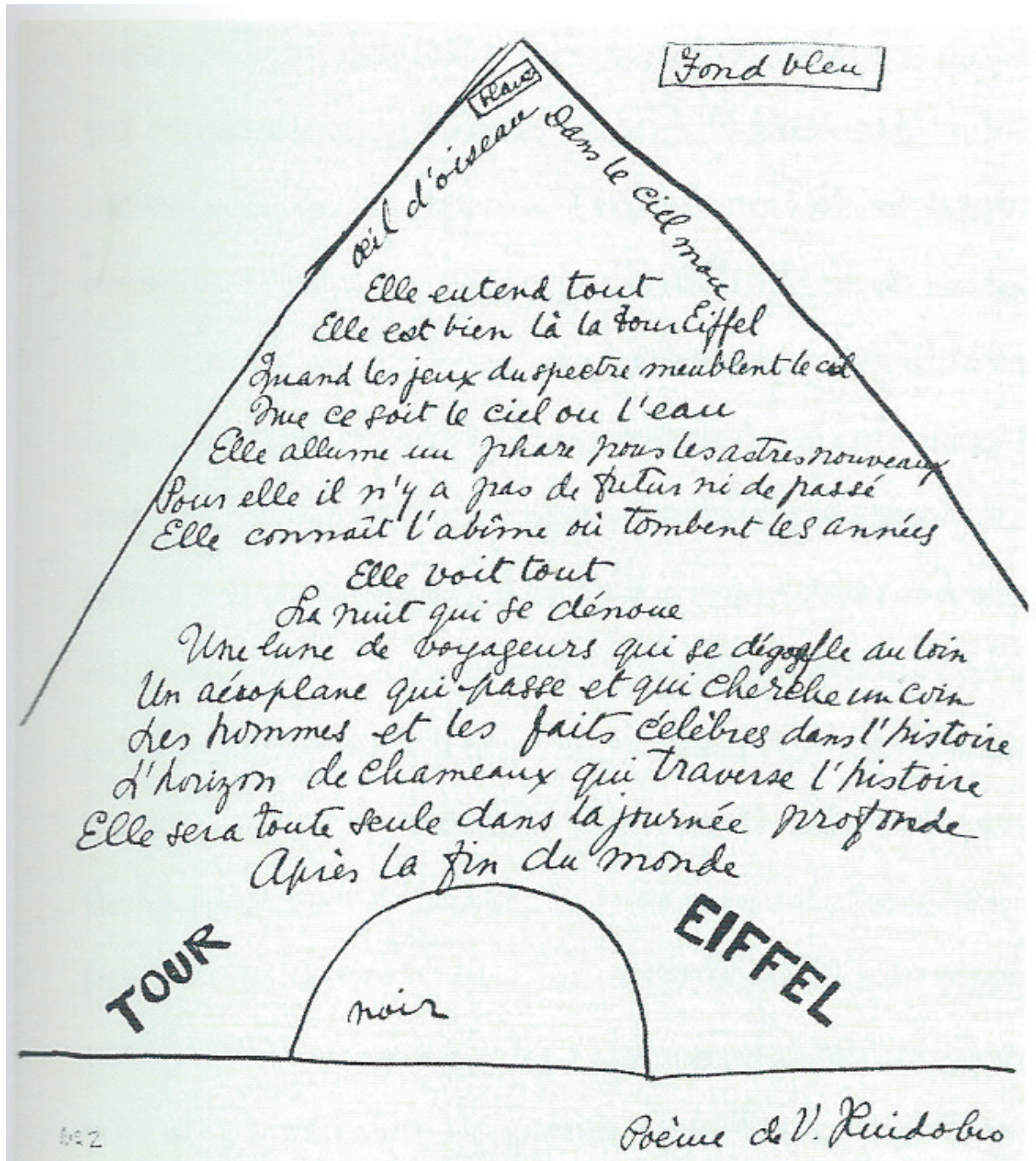


Ojo de pájaro

En el cielo blando

Aquí está la Torre Eiffel

Ella lo oye todo

Cuando los juegos del espectro amueblan el cielo

Ya sea el cielo o el agua

Ella enciende un faro a los astros nuevos

Para ella no hay futuro ni pasado

Ya conoce el abismo donde se precipitan los ańos

Ella lo ve todo

El desenlace de la noche

Una luna de viajeros que se desinfla a lo lejos

Un aeroplano que pasa y busca un cobijo

Los hombres y las hazañas célebres de la historia

El horizonte de camellos que atraviesa la historia

Ella estará del todo sola en el día profundo

Después del fin del mundo

TORRE

EIFFEL

Los sentidos que activa este poema tienen que ver con la concepción de la creación como dispositivo multisensorial ${ }^{20}$ : algo que ya quedaba patente en el ejemplo que acabamos de analizar, pero que aquí responde a un procedimiento distinto. La vertiente creacionista se activa también mediante conexiones imprevistas, aunque no tan singulares (al menos en apariencia) dado el carácter pleonástico de la relación intersemiótica entre la figura y su referente.

Destaca inmediatamente el protagonismo del color azul, que recorta la geometría de la Torre Eiffel, y una combinación cromática muy pura y contrastada: la torre está representada por un triángulo isósceles de un blanco luminoso, el poema en bastardilla negra contenido en el cuerpo triangular sugiere la estructura metálica de la torre. El arco relleno de negro, que dibujan sus extremidades, ofrece la imagen de un túnel o una puerta negra bastante evocadores. Plásticamente, el poema muestra una depuración y un estatismo extremos, que lo diferencian del dinamismo de las diversas representaciones de la Tour Eiffel que pintó en la misma época Robert Delaunay, y también del poema homónimo de 1918. Aquí, la figura funciona como marco del poema y a la vez anticipa el referente de la torre que los versos exaltan. El texto poético, en este caso, no guarda una relación inmediata con

$20 \quad$ El aspecto de la multisensorialidad, junto a la presencia de motivos que remiten al paisaje urbano, el mundo mecánico y el movimiento, revela el matiz marcadamente futurista que caracteriza el periodo creacionista de Huidobro. De hecho, cubismo, creacionismo y futurismo tienen puntos de confluencia. El simultaneísmo es un claro ejemplo de ello: Huidobro concibió objetos simultáneos en colaboración con artistas como Sonia Delaunay, tales como los Robes-poèmes. Las prácticas cubistas, ya sea en la literatura o en la pintura, ponen de manifiesto este rasgo en la técnica de la síntesis; y el dinamismo producido mediante la técnica futurista del divisionismo coincide en gran medida con el cubismo analítico. 
el cubismo ${ }^{21}$. Su estilo se adhiere más a la estética modernista, pese a un lenguaje bastante discursivo, y a la presencia de metáforas de corte dadaísta-creacionista. En este sentido, cabe citar la imagen del aeroplano, omnipresente en la poesía de Huidobro y que entronca con la estética futurista y su fascinación por la técnica y el movimiento.

No obstante, el aspecto multisensorial y dinámico que se apreciaba en el poema "Tour Eiffel" de 1918 queda aquí mitigado tanto por la estabilidad de la figura visible como por la composición poética. Los versos manifiestan una mayor regularidad, apenas fragmentada en comparación con el otro poema examinado, y el esquema de la rima forma pareados. Sólo el primer verso "Elle entend tout" se separa de ese esquema, pero para articularse luego con el verso central, "elle voit tout", tanto a nivel métrico como rítmico. Se resalta de este modo la dimensión todopoderosa y omnipresente de la Torre y su función como testigo de la historia.

La relación entre la figura y el título es aparentemente tautológica, debido a la identificación inmediata del monumento por la retina, que ya de por sí haría innecesaria la lectura del rótulo en mayúsculas TOUR EIFFEL. Sin embargo, descubrimos luego que la lectura de los versos da consistencia poética al cuerpo y a la vez introduce otros niveles de interpretación en conexión con el simbolismo iconográfico. Así, lo que a simple vista corresponde a una iconicidad de tipo imágico (Peirce), desencadena una instancia interpretante que da paso a una iconicidad diagramática/metafórica ('iconicidad secundaria' $)^{22}$. Dicho de otro modo, se establece un sistema de correspondencias entre el mensaje textual y el mensaje icónico, cuya articulación activa la interpretación. Así, el arco negro será a la vez retina escrutadora. El cruce de dispositivos interartiales sirve para puntuar el mensaje y confiere al poema una dimensión ontológica: por un lado, se subraya el carácter universal y sempiterno de la Torre Eiffel; por otro lado, su facultad como vigía, guía y testigo de la historia. En este sentido, la personificación de la Torre Eiffel muestra un paralelismo con la figura del poeta tal como lo concebía Huidobro: poeta guía o "pequeño dios", conocedor de la capacidad transformadora del lenguaje. El contenido que expresan estos dos versos: Elle entend tout (Ella lo oye todo) /Elle voit tout (Ella lo ve todo) está motivado por la forma de la torre, que vista de lejos ofrece la imagen del ojo dominador del Creador rodeado por un triángulo, tal como lo representa la iconografía cristiana. Mediante este desplazamiento del túnel negro a la pupila, Huidobro eleva a la Torre a una categoría

$21 \quad$ El recurso a la geometría triangular para designar metonímicamente a la torre, sí es técnica cubista. Pensemos, por ejemplo, en cuadros donde los cilindros ocupan el lugar de las botellas y las sugieren por semejanza icónica con la geometría esencial. El comentario de Gris es revelador a este respecto: "Cézanne, d'une bouteille, faisait un cylindre. Moi, d'un cylindre, je fais une bouteille". También corresponde a la técnica cubista de la síntesis, la superposición de lecturas simbólicas que activa el triángulo y la síntesis interartial que comporta el poema-pintado. Para una aproximación exhaustiva de este aspecto remitimos al brillante estudio que Rosa Sarabia ha dedicado a La Torre Eiffel de Huidobro: «La Torre Eiffel: emblema de modernidad y síntesis de artes» (Sarabia 2007: 101-145).

22 Esto equivaldría a lo que Göran SONESONN denomina "iconicidad secundaria", en la cual la percepción de la similaridad se produce gracias a la función sígnica. (2001: 47-55). 
suprema y divina. La superposición de estos dos planos de lectura pone de manifiesto una exaltación de la modernidad que la Tour Eiffel encarna. Pero, a la vez, ese gesto ideológico de profanación y el substrato prometeico subyacente, eleva al ser humano a la categoría de "hombre total". De alguna manera se está gestando la idea de hombre que preconizaría Huidobro a partir de su manifiesto titulado "Total" (1932) ${ }^{23}$.

Por otro lado, el aspecto totalizante de la Torre queda patente en su carácter tanto aéreo como acuático ("que ce soit le ciel ou l'eau"), y ello se refleja tanto mediante dispositivos discursivos como plásticos: la forma triangular de la Torre evoca asimismo la vela de un barco, la cual está coronada, cual vigía, por el verso que designa el ojo del pájaro; la figura se ha colocado rodeada de azul, no apoyada en una base firme sino "flotando" en el aire. En el rico sistema metafórico que constituye el poema, ella es también un faro en el mar del cielo. Si a primera vista las técnicas cubistas del análisis y la síntesis parecían poco notorias en este poema, los desplazamientos y las condensaciones que se desprenden del análisis detallado que hemos presentado las revelan.

Así como la percepción primera de este poema revelaba un objeto poético y artístico de apariencia estable, la fase de traducción tampoco auguraba un proceso complejo y no ha supuesto una ardua tarea. Nos limitaremos a señalar algunos aspectos que han atraído nuestra atención y que nos han llevado a operar ciertas modificaciones:

1) Inversión de los dos primeros versos.

Elle entend tout / Elle est bien là la Tour Eiffel Aquí está la Torre Eiffel / Ella lo oye todo

Nos ha parecido oportuno invertir el orden de los versos y arrancar destacando la presencia de la Torre. Por un lado, resulta más coherente empezar citando el referente en lugar de posponerlo. Por otro lado, invertir el orden de los versos nos permite optar por el pronombre anafórico [Ella] en el verso siguiente y así privilegiar el paralelismo fundamental de los versos "Ella lo oye todo / [...] / [...] / Ella lo ve todo". Además, una traducción demasiado calcada sobre el original (Ella está aquí la Torre Eiffel) habría resultado rígida y poco natural en castellano.

2) Realce de ciertas estructuras binarias.

- Los dos versos que coronan la torre formando ángulo:

Oeil d'oiseau / Dans le ciel mou

$23 \quad$ "Total" fue publicado en francés en 1932 en Vertigral, revista del orfismo; luego, en 1933, en La Nación de Buenos Aires, y también se publicaría en el primer número de la revista homónima Total (Santiago de Chile, 1936), fundada por Huidobro como "contribución a una nueva cultura". 
Estos versos ponen de manifiesto un doble paralelismo: un paralelismo plástico, en la disposición de los versos unidos en el vértice del triángulo isósceles; y un paralelismo visual y paronomástico, en la materialidad de la letra:

Oeil [œj] / ciel [sjel]

Oiseau $[\mathrm{wazo}] / \mathrm{mou}[\mathrm{mu}]$

La traducción palabra por palabra (“Ojo de pájaro / En el cielo blando”) convenía en este caso, ya que la regularidad métrica y rítmica que se consigue resulta aún más eficaz que en los versos originales y permite contrarrestar la pérdida de otras rimas en el resto del poema.

- Las oraciones paralelas en versos separados:

Elle entend tout (Ella lo oye todo)

Elle voit tout (Ella lo ve todo)

La separación de estos versos en el poema tiene que ver con la fragmentación propia de la técnica analítica. Era preciso mantener el pronombre personal (Ella). La repetición del pronombre anafórico, junto a la del molde morfosintáctico y la de la palabra "tout" pone énfasis en el poder totalizador de la Torre Eiffel y facilita la aproximación de estos dos versos distantes en el poema. Que ambos versos arranquen con "Ella" y se cierren con "todo", como en el original, es importante por la conexión significante que ello imprime.

3) Recurrencia del pronombre "elle".

La presencia masiva del pronombre anafórico "elle" en el texto original es exigencia gramatical de la lengua francesa, pero a la vez produce un doble efecto: refuerza la presencia de la Torre y lo hace de manera difusa, semejante a la técnica del cubismo analítico. En la traducción, no se ha podido mantener sistemáticamente este rasgo, dado que ello difiere de la convención gramatical en nuestra lengua y resultaría forzado, pero se ha mantenido un equilibrio suficiente para preservar el valor estético que cumple.

Aparte de estos aspectos, la traducción no requería transferir muchos efectos ya que el funcionamiento semiótico de este poema es principalmente holotextual ${ }^{24}$. Aunque paradójicamente el "poema pintado" es menos icónico que el caligrama de 1918, el hecho de enmarcar el texto en la forma de la Torre le da cierto carácter de dedicatoria, a la manera de recuerdo/souvenir de presencia del sujeto lírico.

${ }_{24}$ Entendemos por holotextualidad la materialidad textual considerada como un todo, a partir del
enfoque de B. Schiavetta (1997: 193) 


\section{LA TRADUCCIÓN COMO SEMIOSIS}

Frente al "défaut de langues" mallarmeano, el dinamismo de la creatividad poética comporta un proceso de 'traducción intersemiótica' que no se agota en una única versión. Prueba de ello es la intensidad con la que Huidobro experimenta: multiplicando variantes, superponiendo versiones, alternando formas iconográficas o idiomas, interactuando con artistas plásticos y con compositores: todo cuanto configura las diversas facetas de una gestualidad semiósica de la cual dan buena cuenta los dos poemas seleccionados.

La deriva analítica, que hemos observado a través del análisis y de la traducción, tiene mucho que ver con la semiosis infinita planteada por Peirce. Esta constelación significante quedaba más patente en el texto cubista, pero indudablemente es propia de todo proceso de significación. Lacan daba buena cuenta de ello cuando afirmaba que:

La palabra nunca tiene un único sentido ni los vocablos un solo uso. Cualquier palabra va más allá, sostiene diversas funciones y abarca distintos sentidos. Detrás de lo que un discurso expresa está lo que quiere decir, y detrás de eso que pretende decir, todavía hay algo más que quiere decir, y así sucesivamente ad infinitum (Lacan 1975: 369) 25 .

A tenor de los argumentos presentados en el transcurso de nuestra reflexión, podríamos hacer extensibles estas consideraciones de Lacan al terreno del "lenguaje" icónico. Ello nos lleva a problematizar la concepción saussureana del signo bifaz, restringida al lenguaje verbal ${ }^{26}$.

La poesía moderna, y en particular aquella que opera mediante dispositivos intersemióticos e interartiales, constituye el terreno idóneo para observar el carácter plural y dinámico de la significación y la repercusión de los factores extralingüísticos en la producción de sentido. El sistema metafórico en el que intervienen elementos figurativos, tal como hemos visto en los poemas examinados, confiere a la figura percibida una discursividad y la proyecta hacia un sentido en devenir o significación en acto.

Este aspecto no definitivo de la significación también podría relacionarse con el inacabamiento anatómico explotado por la teoría lacaniana, el cual, a juzgar por el análisis

\footnotetext{
25 Nuestra traducción de «la parole n’a jamais un seul sens, le mot un seul emploi. Toute parole a toujours un au-delà, soutient plusieurs fonctions, enveloppe plusieurs sens. Derrière ce que dit un discours, il y a ce qu'il veut dire, et derrière ce qu'il veut dire, il y a encore un autre vouloir dire, et rien n'en sera jamais épuisé».

26 Lacan invierte el algoritmo saussureano y atribuye una primacía al significante. El concepto lacaniano de significante difiere del de Saussure: Lacan traduce el término Vorstellungsrepräsentanz de Freud, que designaba el representante de la representación. La definición que da se aproxima más al concepto de representamen de Peirce que a la del significante de Saussure: "Un signifiant, c'est ce qui représente le sujet pour un autre signifiant" (Lacan 1966: 299).
} 
textual presentado, se materializa a través del discurso ${ }^{27}$. Lacan plantea que "el inconsciente está estructurado como un lenguaje" y que el sujeto de la enunciación no coincide con el sujeto del enunciado. Sostiene que el lenguaje supone una barrera que separa al sujeto del mundo real ${ }^{28}$.

Del mismo modo que el Sujeto, según Lacan, está barrado por el significante, incompleto, podríamos sostener que los textos también se encuentran barrados, atravesados por significantes enigmáticos que dificultan o impiden una traducción plena. Lo hemos visto al comentar algunos aspectos de la traducción de los poemas "Tour Eiffel” que nos atañen. Un texto (o un poema, un enunciado o un simple vocablo) no es sólo, o no es siempre, lo que aparenta ser. Únicamente el análisis del significante, que se manifiesta de forma discontinua y a través del tejido icónico, es susceptible de revelar significaciones latentes. Y siempre queda algo por colmar, un vacío abierto a la imaginación y a nuevas escrituras y traducciones.

La poesía visual, y de forma notoria la experimentación que esta comporta a partir de las vanguardias históricas del s. XX, podría considerarse como un intento de restituir el goce primordial perdido devolviendo al lenguaje su fundamento icónico y desdibujando los límites entre la imagen y el signo lingüístico.

La fluctuación entre análisis y síntesis observada sobre todo en el primer poema estudiado, así como la conexión de rasgos intersemióticos en ambos poemas, precisamente hace cristalizar la incompletud subjetiva. Si los lenguajes, tomados individualmente, se revelan insuficientes ${ }^{29}$, la articulación entre lo textual y lo pictórico podría considerarse como un procedimiento destinado a lograr aquella langue suprême de la que hablara Mallarmé en "Crise des vers" (1897: 244-245). O como ensamblaje de fragmentos de la "vasija rota" evocada por Benjamin para referirse a la lengua pura. Los "fragmentos" deben permanecer reconocibles y unidos a la vez. De forma análoga, en los poemas analizados y en las traducciones que hemos presentado, el valor específico de los elementos fragmentarios cuenta tanto como lo que adviene de sus conexiones.

Desde esta perspectiva, se puede entender la línea de experimentación intersemiótica e interartial como una búsqueda en el terreno frágil de la representación; y la traducción, no como el resultado de una operación sino como proceso de interacción permanente. $\mathrm{O}$ como síntoma del eterno anhelo por alcanzar una imposible unidad.

\footnotetext{
$27 \quad$ A este respecto conviene considerar el carácter no definitivo del signo según Peirce, que ha llevado a Ubaldo Stecconi a plantear el carácter no definitivo de las traducciones y a oponer el concepto peirciano de la inferencia al de equivalencia. (1994: 161-180).

28 Según Lacan, esta división muestra que el verdadero sujeto es el sujeto del inconsciente, él la representa gráficamente en forma de Sujeto barrado. La barra correspondería a una falla o hiancia. Asimismo, relaciona esta falla con un sentimiento de castración anatómica o incompletud ante la pérdida del goce primordial, que incesantemente el sujeto buscaría completar aún conociendo de antemano el carácter irreductible de la carencia.

29 Extrapolamos el argumento que formuló Walter Benjamin respecto a las lenguas: "Tomadas aisladamente, las lenguas son incompletas" (W. Benjamin 1923: 133).
} 


\section{ObRas CitADAS}

d'Asprer, Núria. 2002. «Des marches cubistes pour monter à la Tour Eiffel ». L'Écriture fragmentaire. R. Ripoll (ed.). Perpignan : Presses Universitaires de Perpignan: 71-87. 2003. "Cubism in translation and cubist iconicity». Divagations iconiques = Iconic divagations. Gian Paolo Giudicetti y Constantino Maeder (comp.). Louvain-laNeuve: Centre d'Études italiennes, Université catholique de Louvain: 77-102. . 2007. «La letra y el signo icónico: apuntes sobre poesía visual». Saltana, Revista de Literatura y Traducción, No 2. http://www.saltana.org/2/docar/0402.htm\#. WohfRKjiY2w

. 2011. "La traducción como dispositivo 'creacionista' en la poética de Vicente Huidobro: el poema pintado "Moulin" y sus versiones". Anales de Literatura Chilena 12(16): 95-115.

Benjamin, Walter. 1923. "La tarea del traductor”. Angelus Novus, Barcelona, Edhasa, 1971. Benko, Susana. 1993. Vicente Huidobro y el cubismo, Caracas: Monte Ávila y F.C.E.

Berman, Antoine. 1985. "La Traduction et la lettre ou l'auberge du lointain", Les tours de Babel. Mauvezin, Trans-Europ-Repress: 35-150. . 2013 [1985]. "El Albergue de lo lejano" (trad. N. d'Asprer). Doletiana, Revista de Traducció Literatura i Arts. no 4 "Filosofia i traducció". [http://webs2002.uab.es/ doletiana/Catala/Doletiana4/Doletiana4.html].

Castro Morales, Belén. 2008. "Los horizontes abiertos del cubismo: Vicente Huidobro y Pablo Picaso". Anales de literatura chilena 9 (9): 149-167.

De Costa, René. 1984. Huidobro: los oficios de un poeta. México, FCE.

Etkind, Efim. 1982. Un art en crise. Essai de poétique de la traduction poétique. Lausanne : L'Âge d'Homme.

Huidobro, Vicente. 1917. “Tour Eiffel”, Nord-Sud (no doble 6-7 de agosto y septiembre de 1917).

. 1919. "Torre Eiffel" (traducción de Cansinos-Assens). Revista Cervantes, septiembre de 1919: 82-84.

. 1936. Revista Total.

. 1964. Obras completas. Braulio Arenas (ed.). Santiago de Chile: Zig-Zag.

. 1989. Obra selecta. Luis Navarrete Orta (ed.). Caracas: Biblioteca Ayacucho. . 1998. Obras poéticas en francés, Waldo Rojas (trad.) Santiago de Chile: Ed. Universitaria.

. 2003. Obra poética. Cedomil Goic (ed). Paris: ALLCA XX, Colección "Archivos".

Lacan, Jacques. 1966. "Subversion du sujet et dialectique du désir". In: Écrits II. Paris: Éditions du Seuil.

.1975. «La fonction créatrice de la parole» en Les écrits techniques de Freud (Séminaire I, 1953-1954). Paris: Points, Seuil.

Mallarmé, Stéphane. 1976 [1897]. "Crise de vers " in Igitur, Divagations, Un coup de dés. Paris: NRF, Poésie/Gallimard. 
Moser, Walter. 2007. «L'interartialité: pour une archéologie de l'intermédialité». In Marion Froger, Jürgen E. Muller (eds.). Intermédialité et socialité. Histoire et géographie d'un concept. Münster : Nodus PubliKationen.

Müller, Jürgen E. 2006. "Vers l'intermédialité : histoires, positions et options d'un axe de pertinence ", Médiamorphoses. Lidentité des médias en questions 16:99-110

Peirce, Charles Sanders. 1958-1966. [1860-1913]. Collected Papers. Vols. 1-6 edited by Charles Hartshorne and Paul Weiss; vols. 7-8 edited by A. W. Burks. Cambridge: Belknap Press of Harvard University Press.

Sarabia, Rosa. 2007. La poética visual de Vicente Huidobro. Iberoamericana / Vervuert.

Schiavetta, Bernardo. 1997. "Holotextualité : signes holotextuels et icônes métriques ", op. cit. revue de littératures française et comparée 10 "Propriétés de l'écriture »: 193-204.

Sonesson, Göran. 2001. "De l'iconicité de l'image à l'iconicité des gestes", Actas del congreso ORAGE 2001 Oralité et gestualité, Aix-en-Provence, juin 18-22, 2001. Ch. Cave, I. Guaïtella y S. Santi (ed.). Paris : Ed. l'Harmattan: 47-55.

Stecconi, Ubaldo. 1994. "Peirce's Semiotics for Translation", in KOINÉ. Annali della Scuola Superiore per Interpreti e Traduttori "San Pellegrino" IV: 161-180.

VVAA. 2001. Salle XIV. Vicente Huidobro y las artes plásticas (catálogo). Madrid: Museo Nacional Reina Sofía. 
